\title{
Education: The 2021 (Post-COVID) Edition
}

\author{
Maharaj-Landaeta Sunita \\ University of Trinidad \& Tobago, Trinidad and Tobago.
}

\begin{abstract}
How to cite this paper: Maharaj-Landaeta Sunita. (2021). Education: The 2021 (Post-COVID) Edition. The Educational Review, USA, 5(5), 138-145.

DOI: $10.26855 /$ er.2021.05.004
\end{abstract}

Received: April 6, 2021

Accepted: April 30, 2021

Published: May 26, 2021

Corresponding author: Maharaj-Landaeta Sunita, University of Trinidad \& Tobago, Trinidad and Tobago.

Email: sam.aruna32@gmail.com

\begin{abstract}
Having marked the first anniversary of the year that no one wanted to remember, many questions about the new normal, shifted educational dynamics and how these alterations have affected teachers and learners worldwide have surfaced. The COVID-19 pandemic resulted in schools being shut-down worldwide; prompting critical questions about what learners are feeling, and their perceptions of this new-normal. With this abrupt shift away from physical classrooms globally, queries persist about whether the adoption of online/remote learning will continue post-pandemic, and how such a swing would influence the international education market. The virus upended many established systems in Trinidad and Tobago's social, economic, political and education systems, around which the country's existence once functioned, propelling it into an era of digital learning which has inadvertently provided the momentous occasion to redesign education cultures in the twin-island. This may be the opportunity to seek out methods of innovating and maximizing learning potential to the fullest. To achieve this, a student perception survey was carried out to gather information on challenges and gaps related to e-learning/remote modalities from the lens of learners, to identify and inform enhanced teaching methods and guidance for planning, programming and evaluations related to this new, 2021 edition of teaching in Trinidad and Tobago. It was crucial to identify students' perceptions and reactions at the ground level and to continuously refine, reengineer, and look for opportunities to upskill and develop teaching methodologies and workplans to meet the needs of learners and help them continue their learning journey in a more efficient manner. The exercise also contributed to identifying existing capacities and gaps to improve upon current education offerings and respond mainly to learners' needs and identify where support needs to be redirected.
\end{abstract}

\section{Keywords}

Remote Education, Online Learning, COVID-19, E-Learning, Student-Perception, Post-Pandemic Education

\section{Education the 2021 Edition}

Now that we have marked the first anniversary of the year that no one wanted to remember, many questions about the new normal, how educational dynamics have shifted and how these shifts have affected teachers and learners worldwide have surfaced. The COVID-19 pandemic resulted in schools being shut-down worldwide; prompting important questions about what children and youths, or learners in general, are feeling, and their perceptions of this new-normal.

Globally, over 1.6 billion learners in over 199 countries (Borkowski et al., 2021) remained out of the classroom well into the latter part of 2020. This new context caused education to change dramatically, with the distinctive increase in e-learning, as teaching was undertaken remotely and via digital platforms. In line with preventive measures, emergency 
plans were adopted by education ministries worldwide. Education institutes and decision-makers did not have the luxury of time to prepare and adapt to remote modalities; there was no trial and testing period, no markers or concrete objectives set, apart from finding a reasonable alternative method to keep young people 'learning' and their minds occupied. Minimizing delays in learning became a main concern. The authorities that be, attempted to find quality resolutions so that children and young people could have some alternative learning method. Hodges, Moore, Lockee, Trust, \& Bold (2020) termed it, emergency remote teaching/learning further defined as "a temporary shift of instructional delivery to an alternate delivery mode due to crisis circumstances” (para. 13)

With this abrupt shift away from physical classrooms in many parts of the globe, queries persist about whether the adoption of online learning will continue post-pandemic, and how such a swing would influence the international education market. Would Hodges et al. (2020) definition of 'temporary', need redefined into a more long-term and permanent fixture in education? This question has become relevant to the T\&T context as well.

At the early stages of the pandemic, many individuals were hopeful that within the first twelve months, a quick solution, in the form of vaccination would be the elixir to this, 'damaging' and seemingly insurmountable situation. Fast-forward to one year later, and vaccination campaigns are now being rolled out, without very realistic testing periods factored in. As such, until such time as a vaccine to deter the spread of the various COVID-19 strains is widely available and distributed, and proven to be effective, the possibility of viral spread continues to pose an obstacle to many forms of in-person interaction, particularly in indoor spaces such as school buildings. Prior to the pandemic, the predominant teaching mode in many countries was traditional face-to-face teaching in classrooms. This was the most common teaching mode as per habits and comfort zone in Trinidad \& Tobago. This Caribbean country was no exception in adapting to new COVID-19 induced norms. The virus upended many established systems in the country's social, economic, political and education systems, around which the country's existence once functioned. One of the most obvious effects of this upset, was the education system, through which the pandemic exposed alarming gaps in equity (Mendes-Franco, 2020).

Discourses around this issue were underscored in social media following the closures of schools. The challenges to facilitate exams in physical spaces and face to face exam preparations, and the realization that blended learning options which included physical attendance to classes being postponed due to the increased numbers of persons contracting the virus, became poignant obstacles (Maharaj-Landaeta, 2020). "To minimize the loss of learning time, emergency remote learning became the modus-operandi, a response which challenged the most socially vulnerable students” (Kalloo, Mitchell, \& Kamalodeen, 2020, p. 1). Having been thrust into online learning, literally overnight, academics have been debating what will become the new normal (Tesar, 2020) for our institutions and teaching practices, and the best way forward.

\section{The Trinidad \& Tobago Context Then}

When lockdowns and restrictions were imposed in 2020, teachers in public and private schools in the twin island were forced to shift completely to remote teaching by utilizing learning management systems, suggested by the local MOE. As discussed in (Maharaj-Landaeta, 2020) article, the rapid launch of online learning management systems (LMS) and, and seemingly loosely planned start to the September 2020 school term via online modalities, provoked varied views and feelings on the efficacy of remote teaching and learning, and forced stakeholders to confront weaknesses of the current offerings.

Opening online classes was not mandatory when lockdowns started in the early part of 2020. In fact, no very specific instructions were given to teachers and students until closer to June when more formal instructions were forthcoming, and by July, training on remote teaching, the broad use of LMS and a new curriculum and syllabus was supplied, so that by September, teachers and students would start the new school term with solid plans.

On the surface, this appeared to be a well-thought through plan, however, as weeks and months rolled by, teachers and learners started discovering gaps in this new teaching/learning system. Indeed, being a new norm, certainly disparities and challenges were expected. Uncertainties surfaced regarding how learners were coping with the remote education modalities and questions on improving pedagogical strategies to make the journey more useful, effective, and efficient, arose. This article centers on perspectives from the end-users; the learners' themselves and concentrates on what they have had to say.

1 E-learning is defined as learning that makes use of Information and Communication Technologies (ICTs). The incorporation of technological resources and innovative education strategies has transformed the teaching and learning processes. 


\section{Aims}

The aim of this inquiry was to gather information on challenges and gaps about e-learning/remote learning through students' views, to identify and inform enhanced teaching methods and guidance for planning, programming and evaluations related to this new, edition of teaching. This was done by capturing views, feedback and experiences from students in Trinidad \& Tobago though a student perception survey. The exercise also contributes to identifying existing capacities and gaps to improve upon current education offerings and respond mainly to learners' needs and identify where support needs to be redirected.

\section{Methodology}

Responses were collected through a perception survey shared remotely with learners that hail from various geographic areas of Trinidad. Teachers were informed of the exercise and reached out to parents who gave permission for their children to participate and fill out the survey/questionnaire or assist their children in responding. Teachers explained the scope and purpose of the perception survey to the students and their parents and asked only that learners be very honest in their responses. The survey remained open from November 2020 to the end of January 2021. Surveys were disseminated digitally, through teachers of primary and secondary classes within local communities to learners of various ages and grade levels who participated in the research. The research was based on convenience sampling and a total of 163 learners, ages 11-17 responded to the exercise which consisted of 6 core, open-ended questions. Two education research assistants helped in compiling the data and observing common patterns from the responses. Although a mixed methods approach was used, a mainly qualitative methodology was used to compile, reduce, analyze and present the data with results emanating from the thematic analysis.

\section{Perception Survey Questions for Students Attending Remote/Online Classes in Trinidad}

1. What (if anything) do you like most about online classes?

2. What (if anything) do you dislike most about online classes?

3. Do you miss being in a physical classroom? Explain

4. How do you feel about possibly returning to a physical, brick and mortar classroom?

5. What is the riskiest/most disturbing thing that you have encountered online/ when in remote class sessions?

6. If you could give your teachers advice on how to make your online classes better, what would it be?

See Figure 1 below for total number.

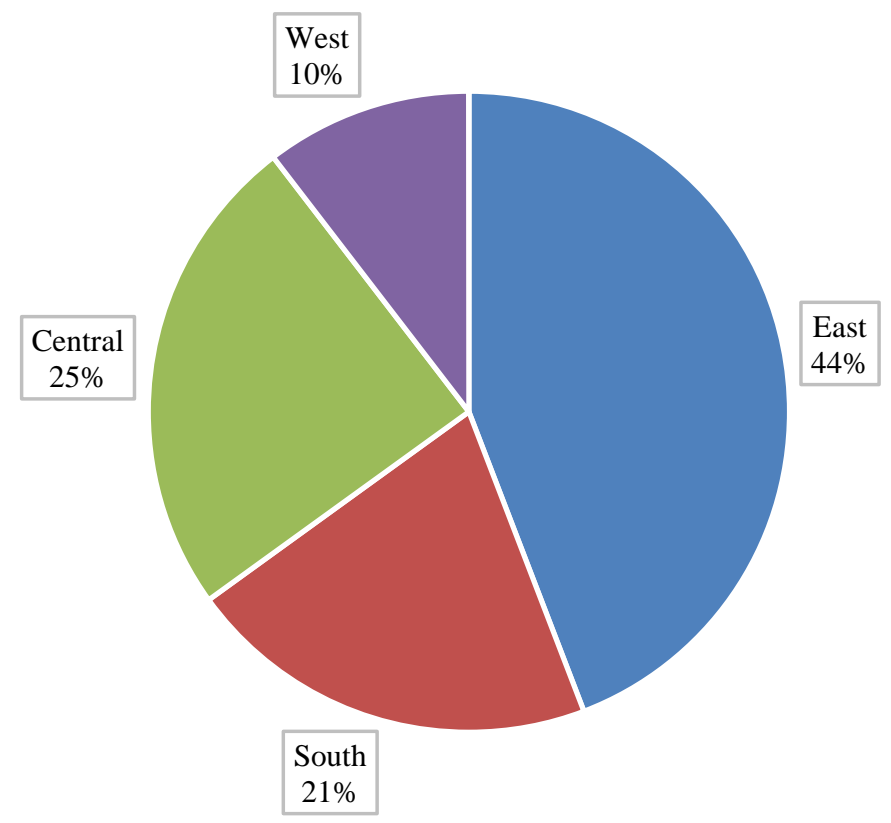

Figure 1. Learners per Area in Trinidad.

Note. Total of 163 learners with ages ranging from 11- to 17-year-old respondents to the student perception survey, per area in Trinidad. 


\section{Online Education in Trinidad \& Tobago Explained}

The T\&T MOE rolled out remote online options for students and teachers. They set-up systems to monitor who logged in, length of sessions, absenteeism rates, and further relied on teachers to let them know which learners had connectivity issues, who lacked internet-enabled devices, who had private donations of devices and more. Teachers explained that some learners accessed tablets and laptops as late as February 2021.

Currently public sector teachers are in discussions about using MS Teams ${ }^{2}$, online systems to carry-out their classes. In 2020, some teachers preferred to pay out of pocket for $\mathrm{Zoom}^{3}$ as the learning management system (LMS) ${ }^{4}$ School$\mathrm{ogy}^{5}$ which they had initially chosen was too difficult to manoeuvre. Consequently, many teachers opted to use Zoom and Google Classroom.

Ministry guidelines, as per the Best Practices in Teaching Online, (Ministry of Education, 2020) document, indicate that online classes must be a minimum of five hours of contact teaching, aka contact screen time, as the inserted suggested timetable schedules span from 9.00 a.m.-2.30 p.m. Further, the MOE revised the existing lesson schemes/syllabus where they removed some aspects of the original syllabus, assuming that this would be enough of an amendment for students to learn well remotely. The 14 teachers who agreed to collaborate by sharing the surveys disclosed that they found challenges managing the online contact time with learners, together with preparations which took place outside of the allotted teaching periods, and then of course, they would sometimes give homework assignments and tests outside of this, just to finish the prescribed curriculum and topics.

\section{Why Students’ Feedback was important}

As with most teaching methods, e-learning/remote learning has its own set of positives and negatives. Decoding and understanding these will help teachers and by extension, the ministry of education to improve upon existing workplans and teaching methods, while creating improved strategies for more efficient delivery of the lessons and ensuring an uninterrupted or smoother learning journey for students. The responses of students on their experiences are meant to help us decode what is working and what is not and is by no means a judgement call on the work of teachers who are also trying to find pathways to coping with the new 2020/2021 phenomena and norm.

\section{Students’ Responses as follows:}

1) What (if anything) do you like most about online classes?

- $\quad 44 \%$ of the respondents indicated they liked not having to wake up early and not having to spend time in traffic.

- $16 \%$ liked the convenience of using computers as teachers can now research and show videos of topics, use online resources, and teach with more visual aids.

- $15 \%$ responded they felt safer at home as they would not be exposed to illnesses.

- $13 \%$ of learners shared that they preferred studying at home as they no longer had to put up with bullies they encountered in their "in-person" classes.

- $\quad 8 \%$ of respondents said they liked doing class from the comfort of home/their room, and it was easier to enter remote classes.

- $4 \%$ of students said that this modality was also slightly more environmentally friendly as one does not need to print resources anymore.

2) What (if anything) do you dislike most about online classes?

Students generally felt that their online learning was difficult to navigate, and they approached their studies with a mixture of anxiety and excitement of the unknown. They were lukewarm about some aspects of online learning, particularly related to homework, practice exercises and tests outside of class time. The results related to this question were surprising as the majority of students held aligned views. Of the 163 respondents, 141 different aged learners, from distinct grades and various locations across the country, indicated that the homework workload was tremendous. It was simply too much to cope with especially after a full day of 'on-screen' engagement. Some students expressed starting

\footnotetext{
2 https://www.dummies.com/software/microsoft-office/how-to-use-microsoft-teams/.

${ }^{3}$ Learn more about ZOOM at: https://biz30.timedoctor.com/how-to-use-zoom/.

${ }^{4}$ Learning Management System (LMS) is an online education hub that provides a large and indispensable set of features to support educational activities such as classroom learning, distance education and continuing education.

${ }^{5}$ Learn more about Schoology at: https://www.schoology.com/.
} 
homework exercises and staying up past midnight to make deadlines.

\section{Sample of students' comments:}

- Some teachers give a lot of homework and do not understand that we have other subjects/assignments to do as well.

- I start homework as soon as classes finish online, and do not finish until very late in the night. I am always tired.

- I do homework for many hours just to meet my teachers' deadlines and then they give a general grade, it is not like they even go through all the exercises, so we know what we are doing right or wrong.

- I like sports and going outside. Since we have online classes all I do is sit down and try to finish homework, and I do not think my teacher even checks all the work that I did. She just looks at if we submit on time and gives and average grade. When I ask her how I could improve she often doesn't give me an answer.

- We have 11 subjects, and each teacher thinks that giving us plenty homework will make us learn. I get 100 questions in Maths alone, every teacher sends so much homework, and they do not care if we know what we are doing, or if we understand. They think that they are good teachers if they give us so much homework, but none of them have the time to correct the homework or explain all the concepts in class. Then they give us a test. I do not like school. I am not learning.

- I am often anxious that I will not be able to join and maintain access to online classes and assignments.

- Teachers think that because we are doing online classes, we have so much extra time. That is not true. If anything, I have less time now. I am frustrated. I am not learning anything

- My internet does not work all the time and I don't always submit all the homework on time. My grades are low because of this. I feel bad. I feel stupid. I wonder if I am the only one who does not understand and who cannot finish the work the teacher is giving. I mean, a teacher would not give us what we cannot handle right?

- Why is the workload so overwhelming? I just can’t keep up.

- I find it impossible to actually learn anything new through my online classes.

The feedback related to homework and completion of assignments was generally negative and seemed to be a main reason for concern. When teachers give distance-learning assignments, it was important from the students' point of view that they are assigned at an early stage, that the assignment is clear, that they know what further steps may be needed, and be given proper feedback and know where they went wrong, and areas to be corrected.

Apart from the issue of homework and assignment completion, learners also highlighted challenges such as not having a device or internet connectivity which made it difficult to keep up with the class learning. Others missed socializing with friends and teachers. Some spoke of having too many online groups and their timetables being disorganized. Few were disillusioned because they were not tech-savvy, and many did not like how heavily classes depended on good Wi-Fi to carry on a class. Students complained they could not see what the teacher was writing on a physical whiteboard, a clear indication that teachers were trying to simulate physical classroom behaviours in the online setting, perhaps as they were not extremely efficient in managing online modalities; an indicator that perhaps more specialized teacher training is required to better manage online and distance classes.

A few students used the term, feeling 'drained' when they thought of online classes. They felt that online classes now were harder than the face-to-face classes. The researcher found it concerning to note the overall general tone of uncertainty and negativity associated with students' perceptions of online learning, or perhaps the excessive homework exercises.

Added to this the use of the words 'stressed' and 'frustrated' frequently emerged throughout the responses. Phang (2017) indicates that "Toxic stress weakens the architecture of the developing brain, which can lead to lifelong problems in learning, behaviour, and physical and mental health" (para. 9) Teachers therefore need to be cognizant that they do not want to create a learning environment which could inadvertently promulgate toxic stress. Teachers may not recognize that in being keen for their students to learn and pressing them with excessive homework, they may have been unknowingly creating a toxic learning environment. This may be an area teachers may want to pay closer attention to.

In January 2021, local Guardian Trinidad \& Tobago newspaper (Paul, 2021) ran a story about 14-year-old student who committed suicide and the question of online associated depression issues were raised, especially because the generally quiet student, had had an argument about schoolwork with a relative right before choosing this outlet. Speculation that the lockdown, lack of activities and challenges to cope with online studies may have contributed to his demise.

Although one cannot be certain what prompted this final tragic act, it does provoke us to deliberate on how we could lessen the stress and frustration of young persons and how our actions as teachers may contribute to, and compound their existing frustrations, especially within the new limited reality of lockdowns, less socialization and overall prohibi- 
tions brought on due to the pandemic.

Even though it may be an unwanted role and additional responsibility, unavoidably, supporting the mental health needs of online students has become an even more critical part of the education mission of teachers. The radical change in lifestyle can feed loneliness, anxiety and even lead to depression for students (and other stakeholders). Teachers are now at the front line of responsibility for identifying emotional and mental health issues, as they are spending endless hours with these learners. This is discussed in-depth in (Patterson Lorenzetti, 2015) article, Supporting the Mental Health Needs of Online Students. Poignant is that even before the shift to online modes due to COVID-19, mental health needs and psychosocial support had been an area of concern within the education field.

One pupil commented, "Some of my teachers have lost touch with reality, and no longer understand the struggles students have. They pile on extra work in my school which is stressful. They also get angry when we do not know something, but when we don't know it's usually the result of them neglecting the quieter students in class. They only choose a select set of students to answer questions who are fast and who already know the answers, so they can keep the class moving. How does this help me? Or any of the other students who genuinely don't know? This has led to us falling behind and being frustrated. If they could reconnect with students better and reduce the level of stress, that will be great as many students now suffer depression and they can’t cope”.

3) Do you miss being in the physical classroom?

Students were generally missing their physical classes, they appreciated when they had classes and there were longer breaks and lunch, so they could finish homework within that time and be with friends.

Other learners missed their classmates, who they said made school somewhat manageable as they had peers with whom to share their struggles. Most liked having persons to talk with face to face.

$57 \%$ of respondents felt that their academic work was now affected, and they were falling behind. Some admitted to not being able to pay attention to online classes for long; they sometimes dropped out of class sessions, claiming internet challenges. Others admitted to cheating for assignments and exams just to manage and finish the set work.

Students also believed that their social skills were hampered but emphasized that that did not mean they wanted to return to school. Others felt being in the face-to-face class would have been easier, because they understood better when the teachers explained in person. They missed not being able to make jokes with friends during the class and even getting into trouble for making noise. They underscored that it was easier to focus on schoolwork in a classroom rather than online, because at home there were many distractions.

Some learners indicated they felt strain, starting with the physical strain on the eyes as many were unaccustomed to squinting at poorly adjusted computer screens in suboptimum ambient lighting which could possibly subject them to eyestrain that can have lasting effects. Apart from the physical strain they described feeling, "mentally strained" as well.

4) How do you feel about possibly returning to a physical, brick and mortar classroom?

This question yielded some mixed feelings. As much as students wanted to have some face-to-face interactions with peers and teachers, and they felt that some in-person explanations and tutorials would be valuable, $85 \%$ was sceptical about returning on a full-time basis. Most learners suggested going out only 2-3 days per week. Some felt they would not remember how to communicate with others when face to face. One student said, "Being alone has left scars in people's heads, I don't remember how to talk, I only know how to text now".

$63 \%$ of the surveyed mentioned being fearful of contracting the virus, while they also indicated that they had gotten accustomed to this new online school routine (even with its flaws).

Over $67 \%$ of respondents used words such as nervous and anxious to describe the possibility of returning to brick-and-mortar classes. The rest expressed feeling happy and excited at going back into a classroom because they felt mentally drained from the stress of online tests and work. However, interestingly the minority that wanted to return to school on a full-time basis were those that were bored or those looking forward to benefitting from the school feeding program, as they had less to eat since they were made to stay home due to pandemic closures.

5) What is the riskiest/most disturbing thing that you have encountered online/when in remote class sessions?

Students explained that they had, on more than one occasion, been exposed to risky content including strangers entering online classes (of primary and secondary students) and displaying images of a sexual nature or being intrusive and disruptive. In one instance, a stranger entered a primary level classroom and used obscene language. Subsequently the teachers and ministry tried to secure the learning sites even more. This certainly disturbed learners who had been exposed. Some had no idea what was happening, but others admitted to feeling uncomfortable and "shocked".

A few learners in the upper grades, also admitted to getting distracted with gaming (even while classes were in session). While younger children, confessed to playing more online games, older students used words like "getting hooked", "getting distracted" and spending "too much-time" playing on-line games, but "not being able to help them- 
selves”. This causes one to ponder whether these learners might be at-risk of online gaming disorders ${ }^{6}$.

6) If you could give your teachers advice on how to make your online classes better, what would it be?

Learners across the board agreed on the fact that teachers needed to ease up on the workload, because being at home does not mean they should give loads of unnecessary assignments. Also, students advocated for educators to "teach and explain more" and "give less exercises and homework". The argument being that they could not practice what they had not mastered or not learnt well in the class. They want teachers to be patient because not everyone would understand the topic as they would in the physical classroom.

Pointed was that students sympathized with their teachers. They knew teachers themselves were probably struggling with the new teaching method. Most students believed their teachers were just "mis-led", "confused" or did not know how badly they were affected with the excessive homework. They opined that "teachers also are struggling" with the rapid transition to online learning, understanding that teachers also needed to adapt and knowing that their teachers "might not be tech savvy". Many of the upper grade students commented that teachers need more training to deliver better online education.

Survey responses highlighted requests to lessen the amount of work being sent and asked teachers to be more flexible with the due dates for assignments because often, submissions were recorded as late.

Generally, learners did not appreciate having to complete tests, which would be marked and graded, after contact hours. They admitted to needing time to study after school, but many indicated that they did not have the opportunity to revise or study because their evenings were spent working on assignments for at least five or six hours.

Upper grade students also mentioned that teachers needed to be their advocates and voice, and even though the ministry had demands to finish certain numbers of lessons within a given space of time, teachers needed to advise the ministry on the children's behalf. Learners had identified a lack of flexibility in terms of course/topic-completion, however, they perceived this inflexibility as stemming from the ministerial level and not from their educators.

Learners had observed a lack of balance with many juggling 7-8 subjects daily. They commented, "With online classes time seems to run out, if we tell our teachers we need more time to do a particular assignment because we are trying to manage other assignments from other subject/classes, they get upset and suggest that we are placing a higher priority on the other subject areas. Some students put their best effort into doing the assignments, but we need our teachers to understand that it is sometimes too much work and we just need more time”.

\section{Limitations}

The current study has several limitations that could be addressed within future research. While the survey aimed to gain insight about students' experiences in online classes in Trinidad \& Tobago it was not designed to be fully representative and reached only 163 learners. Hence although the findings are valuable, one would need to be cautious in claiming that the responses are fully representative of all Trinbagonian students' experiences. Further obstacles also prevented the researcher from reaching learners in the twin sister isle of Tobago and it is important to note that resources and environments differ on both islands, hence one might not be able to apply the results across the board to represent learners from Tobago. Additionally, in retrospect, the researcher realized that follow-up questions with learners may have been necessary to better understand the complexities of their situations and challenges faced. Moreover, upon deeper reflection and analysis, the researcher recognized that it would also be useful to get teachers views related to the new online teaching methodologies, in order to present a balanced, realistic and fair view of online teaching in T\&T classrooms today. The exploratory evaluation of the open-ended questions undoubtedly raises useful issues for further research work, such as whether students' satisfaction rates and overall performance might increase if homework and after school assignments are lessened. It would also be interesting to delve into, and measure how online learning has affected the mental health of learners, and other educational stakeholders, including teachers and even parents of learners.

\section{Conclusion}

The era of digital learning has provided a momentous occasion to redesign education cultures. It is necessary to ex-

\footnotetext{
${ }^{6}$ Internet gaming disorders are continuous and repeated involvement with video games, often leading to significant daily, work and/or educational disruptions and has been suggested by America Psychiatric Association (APA) as a tentative psychiatric disorder that requires further study (Diagnostic and Statistical Manual of Mental Disorders).

https:/www.ncbi.nlm.nih.gov/pmc/articles/PMC6876823/\#: :text=Internet\%20gaming\%20disorders\%20are\%20defined,requires\%20further\%20stud y\%20(Diagnostic\%20and
} 
plore and seek out methods of innovating and maximizing learning potential to the fullest. Based on the responses of the student perception survey, teachers in Trinidad may consider customizing blended teaching methods and being selective while opting for practice exercises that help and enable learners. It is crucial to know how the students are feeling and reacting at the ground level and to continuously refine, reengineer, and look for opportunities to upskill and develop teaching methodologies and workplans to meet the needs of our learners and to help them continue their learning journey in a more efficient manner.

Underneath the growing pains of virtual education, and as the world continues to wade through the global pandemic, it is obvious that with some reflection and refinement, there are benefits that learners can reap, with research, dedication, and flexibility of stakeholders (especially teachers and the local MOE). While there are some students who are thriving through online learning, the toll of the virus, isolation, increased workloads and other associated effects are rising among many students, staff and teachers as they negotiate new identities and experiences. The associated challenges should not be underestimated, and this new learning modality must be scrutinized to fill any gaps. Every institution and stakeholder, including educators must address these challenges that threaten the well-being of those in their charge, and ensure the 2021 Edition of learning is turned into a high quality, efficacious, flexible, realistic study mode that reaches our end users in a positive fashion.

We do not know what the future holds, nor do we know if online teaching and learning will make up a permanent fixture within the educational landscape. What we do know is that within this version of learning that we offer now, we need to think of it as a growth experience and focus on long-range strategic planning, focused sustainable professional development, and student success. Undoubtedly teachers play a significant role in moulding students' success, once they understand their importance and how their choices affect their learners, they will be well on the way to improving remote learning experiences for the 2021 edition of learning and beyond.

\section{References}

Borkowski, A., Ortiz Correa, J. S., Bundy, D. A., Burbano, C., Hayashi, C., Lloyd-Evans, E., Reuge, N. (2021). COVID-19 Missing More Than a Classroom. The Impact of School Closures on Children's Nutrition. Innocenti UNICEF, Office of Research. Florence: Innocenti Working Papers UNICEF. Retrieved March 15, 2021, from https://www.unicef-irc.org/publications/1176 -covid-19-missing-more-than-a-classroom-the-impact-of-school-closures-on-childrens-nutrition.html.

Hodges, C., Moore, S., Lockee, B., Trust, T., and Bold, A. (2020, March 27). The Difference Between Emergency Remote Teaching and Online Learning. Retrieved March 12, 2021, from er.educause.edu: https://er.educause.edu/articles/2020/3/the-differencebetween-emergency-remote-teaching-and-online-learning.

Kalloo, R., Mitchell, B., and Kamalodeen, V. (2020, July 29). Responding to the COVID-19 pandemic in Trinidad and Tobago: challenges and opportunities for teacher education. Journal of Education for Teaching, 46(4), 452-462. Doi: https://doi.org/10.1080/02607476.2020.1800407.

Maharaj-Landaeta, S. (2020, November 17). Education in the Era of COVID-19: Innovative Solutions to Real Challenges. The Educational Review, USA, 4(11), 193-198. doi: http://dx.doi.org/10.26855/er.2020.11.002.

Mendes-Franco, J. (2020, April 16). COVID-19 exacerbates inequalities in Trinidad \& Tobago's education system. Retrieved July 20, 2020, from GlobalVoices.org: https:/globalvoices.org/2020/04/16/covid-19-exacerbates-inequalities-in-trinidad-tobagoseducation- sys-tem/202.

Ministry of Education, T. (2020, September). Resource Packet for Educators. Port of Spain: Ministry of Education. Retrieved March 19, 2021, from https:/www.moe.gov.tt/wp-content/uploads/2020/09/Best-practices-in-teaching-online-formatted.pdf.

Patterson Lorenzetti, J. (2015, November 12). Supporting the Mental Health Needs of Online Students. Retrieved March 27, 2021, from facultyfocus.com: https://www.facultyfocus.com/articles/online-education/supporting-the-mental-health-needs-of-onlinestudents/.

Paul, A.-L. (2021, January 24). 'Children under pressure,' boy, 14, dies by suicide. (T. a. Guardian, Editor, \& Trinidad and Tobago Guardian) Retrieved February 18, 2021, from https://www.guardian.co.tt/news/children-under-pressure-boy-14-diesby-suicide-6.2.1279871.8df7738b9e.

Phang, K. (2017, July 13). Toxic Stress: How the Body's Response Can Harm a Child's Development. Retrieved February 20, 2021, from nationwidechildrens.org: https://www.nationwidechildrens.org/family-resources-education/700childrens/2017/07/toxicstress-how-the-bodys-response-can-harm-a-childs-development.

Tesar, M. (2020, June 1). Towards a Post-Covid-19 'New Normality?': Physical and Social Distancing, the Move to Online and Higher Education. Sage Publishing, 18(5), 556-559. doi: https://doi.org/10.1177/1478210320935671. 